\title{
Carotid artery stenting in a single center, single operator, single type of device and 15 years of follow-up
}

Victoria Mayoral Campos ${ }^{1,2^{*}}$ (D) José Andrés Guirola Órtiz ${ }^{1,2}$, Carlos Tejero Juste ${ }^{3}$, María José Gimeno Peribáñez ${ }^{1,2}$, Carolina Serrano ${ }^{1}$, Cristina Pérez Lázaro ${ }^{3}$, Ignacio de Blas Giral ${ }^{4}$ and Miguel Ángel de Gregorio Ariza ${ }^{1,2}$

\begin{abstract}
Background: Revascularization with carotid stent (CAS) is considered the therapeutic alternative to endarterectomy (CEA). However, its role compared to CEA remains questioned, mainly due of the heterogeneity of long-term results. The objective of this study was to report the efficacy and durability of CAS in terms of stroke prevention in a "real world experience".
\end{abstract}

Method: This was a single-center retrospective analysis of 344 patients treated with CAS between January 2001 and December 2015.

The primary outcome of the trial was stroke, myocardial infarction, or death during a periprocedural period or any stroke event over a 15-year follow-up. The secondary aim was to identify risk factors for 30-day complications, long-term neurological complications, and intra-stent restenosis.

Results: The primary composite end point (any stroke, myocardial infarction, or death during the periprocedural period) was $2.3 \%$. The use of an EPD was protective against major complications.

Long-term follow-up was achieved in 294 patients (85,5\%) with a median of 50 months (range 0-155 months). Fifty-six (16,3\%) died within this period, most commonly of nonvascular causes (4 patients had stroke-related deaths). During the follow-up period, 8 strokes and 3 TIAs were diagnosed (3.2\%).

ISR determined by sequential ultrasound was assessed in $4.4 \%$ of the patients and remained asymptomatic in all but 2 patients (0.6\%). All patients with restenosis underwent revascularization with balloon angioplasty.

Conclusion: The long-term follow-up results of our study validate CAS as a safe and durable procedure with which to prevent ipsilateral stroke, with an acceptable rate of restenosis, recurrence and mortality.

Keywords: Neurointervention, Endovascular treatment, Carotid stenting, Revascularization, Carotid artery, Carotid artery stenosis, Stroke, Long-term follow-up

\section{Background}

Cerebrovascular disease is an increasing global health problem, responsible for $10 \%$ of deaths, worldwide (Dorn et al., 2012). Carotid artery stenosis due to atherosclerotic disease is liable for approximately $20-30 \%$ of these strokes (Chaturvedi et al., 2005; Roger et al., 2011),

\footnotetext{
*Correspondence: vickymayoral@gmail.com

${ }^{1}$ GITMI (Grupo de Investigación en Tecnicas de Minima Invasión) del

Gobierno de Aragon, Zaragoza, Spain

${ }^{2}$ Servicio de Radiología intervencionista, Hospital Clínico Universitario Lozano Blesa, Avenida San Juan Bosco 15, 50009 Zaragoza, Spain

Full list of author information is available at the end of the article
}

with this stroke subtype associated with the highest rate of recurrence (Coutts et al., 2008).

The American Heart Association/American Stroke Association (AHA/ASA) (Kernan et al., 2014) considers revascularization with stent to be a therapeutic alternative to surgery to prevent stroke, in select patients with symptomatic carotid artery stenosis, although in many centers surgery is still considered as the gold standard. While this recommendation is supported by multiple large randomized clinical trials, including CREST (Bonati et al., 2015; Brott et al., 2016), we currently lack long-term outcome data for CAS procedures. Further, 
critics of CAS cite that this approach fails to remove the plaque, which can result in restenosis and potentially new stroke events. With an aging population and an increasing life expectancy, long-term outcomes following CAS are now needed to guide treatment appropriately.

The objective of this study was to report the efficacy and durability of CAS in terms of stroke prevention. The primary outcome of the trial was stroke, myocardial infarction (MI), or death during a periprocedural period (30 days after treatment), or any stroke event over a 15-year follow-up. The secondary aim was to identify risk factors for 30-day complications, long-term neurological complications, and intra-stent restenosis (ISR).

\section{Methods}

This paper has been approved by the Ethics Committee in our Hospital.

\section{Patients}

An observational retrospective study was performed using material retrieved from a database describing a single-center patient cohort. The study included 344 patients treated with CAS between January 2001 and December 2015. All patients had carotid artery stenosis documented by duplex ultrasound (toshiba aplio 300) and confirmed by angiography. In those cases in which the diagnosis was doubtful or unreliable, CT-angiography $(36,3 \%)$ or MRI-angiography $(45,3 \%)$ was performed.

Inclusion criteria were: age $>18$ years, with no upper limit; symptomatic stenosis $>50 \%$; asymptomatic stenosis $>60 \%$, with more than one risk factor for future embolism (i.e. progressive carotid stenosis, silent stroke documented by neuroimaging, contralateral carotid occlusion with high-risk carotid plaque, or microemboli detected by transcranial duplex ultrasound).

Exclusion criteria included: life expectancy $<1$ year; intracranial hemorrhage or major surgery within 30 days of the procedure; uncontrolled arterial hypertension or coagulopathy; contraindications to heparin or antiplatelet therapy; a lack of percutaneous vascular access.

\section{Pretreatment evaluation}

The human group that worked as a team in all the procedures was formed by neurologists and interventional radiologists, with whom an anesthetist collaborated. The team performs a joint assessment of each case to determine the most appropriate treatment for each patient.

Pretreatment evaluation included an assessment of the degree of stenosis using noninvasive imaging, a neurological assessment (NIH stroke scale), laboratory results, and a 12-lead ECG. Any changes in medication were agreed by the medical team.

All patients agreed to, and provided, written (signed) informed consent. Patients received antiplatelet therapy with daily oral entericoated aspirin (100 $\mathrm{mg}$ per day) and clopidogrel ( $75 \mathrm{mg}$ per day) at least 3 days prior to the procedure. Patients using long-term anticoagulation had their treatment converted to heparin.

\section{Procedure protocol}

CAS procedures were performed by 2 interventional radiologists, one with more than 30 years of experience in endovascular techniques. In most patients, and when practicable in the hospital setting, endovascular treatments were performed within the first 2 weeks of becoming symptomatic (76,4\%), except in those cases where there was a high risk of bleeding and hyperperfusion syndrome (Kernan et al., 2014; Furie et al., 2011; Sacco et al., 2006).

The right common femoral artery (CFA) is the preferred access for CAS. The left CFA and the brachial artery were alternative accesses if the right CFA was not possible. A 6 French sheath and a 0.035" hydrophilic wire (Terumo Europe) is advanced into the aorta under direct fluoroscopy. A multiside-hole pigtail catheher (Cook Medical, Bloomington, IN) was placed over the guide wire and positioned in the aortic arch. An aortogram was obtained with $30 \mathrm{~cm}^{3}$ of contrast at $15 \mathrm{ml} / \mathrm{s}$ (Ioversol $320 \mathrm{mg} / \mathrm{ml}$ ).

Catheter selection for CCA was chosen depending on the aortic arch anatomy. The used catheter was a $5 \mathrm{Fr}$ Vertebral (Terumo, Europe). Selection of great vessels in the setting of Type III arch typically required a reverse curve catheter type Simmons II (Terumo Europe) or a brachial approach when femoral access was not possible. A carotid angiography was performed in AP, lateral, and intra-cerebral (Towne and lateral views).

A $260 \mathrm{~cm}$ safety "J" guidewire was advanced to the ECA, and a $6 \mathrm{Fr}-90 \mathrm{~cm}$ guiding catheter (Flexor - Cook Medical, Bloomington, IN) was then placed in the CCA. Anticoagulation was infused with a bolus of $80 \mathrm{IU} / \mathrm{kg}$ of UFH. In scenarios of appropriate anatomic conditions an embolic protection device (EPD; Accunet, Abbott Vascular, Santa Clara, CA) was deployed distally (4.5$6.5 \mathrm{~mm}$ ). The authors tried to use EPD in all patients regardless of the type of plaque. A self-expanding carotid stent system (Acculink, Abbott Vascular, Santa Clara, CA) was then placed across the stenosis.

Predilation of the stenosis after the placement of the EPD and before stent deployment was controversial. The IR's performed predilatation when the stent cannot be safely advanced. If predilation was desired, a $5 \times 20 \mathrm{~mm}$ diameter balloon should suffice and atropine was given prophylactically if bradycardia ensues (procedure was perform always with an anesthesiologist).

A repeat arteriogram was performed. Any residual stenosis exceeding $30 \%$ was treated with a $5 \times 20 \mathrm{~mm}$ diameter balloon angioplasty and atropine was given 
prophylactically. Two antiplatelet agents, clopidogrel (75 $\mathrm{mg}$ for 4 to 6 weeks), and aspirin (100 mg; used indefinitely),

\section{Data collection and follow-up}

We retrospectively collected all clinical, angiographic, and procedural data. A neurological specialist performed the clinical follow-ups, with carotid ultrasound at 1, 3, 6, and 12 months after the intervention, and annually thereafter. If there was any alteration in carotid ultrasound (PSV $>200$ or ICA/CCA ratio $>3$ ), a selective angiogram was performed.

All patients were treated with BMT. We made strict control of blood pressure to keep levels < 120/80, LDL cholesterol to keep levels $<70$ and blood sugar control to keep levels of HbA1c $<7 \%$. We make patients aware of a healthy lifestyle attempting to be physically active, non-smokers and trying to maintain a healthy body weight.

\section{Definitions}

Patients were considered symptomatic if they presented with ipsilateral amaurosis fugax, transient ischemic attack (TIA), or ischemic stroke within 4 months of the procedure. Stroke was defined as a neurological deficit of cerebrovascular cause that persists beyond $24 \mathrm{~h}$, or a new cerebrovascular lesion in neuroimaging. TIA was defined as a focal neurologic deficit that resolves completely within $24 \mathrm{~h}$. A MI component was defined on the basis of elevated myocardial enzymes plus either symptoms or electrocardiographic evidence of an event. Technical success was defined as restoration of cerebral flow through the lesion, with a $>20 \%$ improvement in stenosis and a residual stenosis of $<50 \%$. Major complications included death, stroke or MI. Minor complications were defined as all those that do not require any intervention. Global complications were defined as the sum of major and minor complications. Restenosis was classified when the intra-stent stenosis was greater than $50 \%$ (Higashida et al., 2009). Efficacy was defined as the absence of stroke during follow-up. Neurological death was defined as that caused by stroke or associated with procedural complications. Vascular death was defined as that caused by MI or peripheral artery disease (PAD).

\section{Aims and statistical analysis}

The primary aim of the study was to analyze stroke, MI, or death during the periprocedural period (30 days after treatment), or any stroke-event over a 15-year follow-up. We also evaluated the long-term behavior of the implanted carotid stents in terms of patency rate and the need for reintervention. Our secondary aim was to identify predictive risk factors for 30-day complications, long-term neurological complications, and ISR.
Statistical analyses were with the SPSS software (Released 2012; IBM SPSS Statistics for Macintosh; Version 21.0. Armonk, NY: IBM Corp). Normality was tested using the Kolmogorov-Smirnoff test. Quantitative variables were expressed as mean values with standard deviations. Qualitative data were expressed as the total number of events with percentages. Continuous variables were analyzed using either the Student's t-test or the Mann-Whitney U test. The Chi-squared and Fisher's exact tests, or likelihood ratios, were used for categorical variables. Survival curves were calculated using the Kaplan-Meier method and were compared with the log-rank test. All tests were considered statistically significant if the $p$ value was less than 0.05 .

\section{Results}

From January 2001 through December 2015, a total of 344 patients with a median age of 70.79 years (range 44-86) were treated with CAS. The procedure was more common among men than women, with $86 \%$ of patients male. All but 35 (10.2\%) patients were symptomatic. Demographics, risk factors, and patient morbidities are listed in Table 1. Hypertension, dyslipidemia, and smoking were the most potent, prevalent, and treatable risk factors for stroke.

The carotid stent deployed was the Acculink with no procedures aborted before insertion of the stent. Protection devices were used for $60.2 \%$ of patients. Post-stent balloon dilatation was performed in $73.8 \%$ of patients, with predilatation necessary for 20/344 arteries (5.8\%).

Technical success was achieved in 335 of the 344 arteries (97.4\%) treated. Although it was possible to pass a wire through the stenosis in 9 patients, complete stent expansion was not achieved for this group.

The primary composite end point was $2.3 \%$ (Table 2). Strokes occurred in 8 patients, with the only death related to severe bleeding in the context of a hyperperfusion syndrome. None of the stroke events were the result of an acute stent thrombosis. There were no patients with MI.

We undertook exploratory analyses of the composite outcome of stroke, death, or procedural myocardial infarction. These analyses suggested that use of an EPD was protective against major complications (Table 3). In addition, EPD-use led to a reduction in major complications, falling from $5,1 \%$ without the use of EPDs to $0.5 \%$ with EPDs $(p=0.005)$.

For long-term analysis, patients were followed for a median of 50 months (range $0-155$ months). A total of 50 patients were lost to follow-up (Table 4), with long-term follow-up achieved in 294 patients (85.5\%). Fifty-six (16.3\%) patients died within this period, including 4 stroke-related deaths, and 52 non-lesion 
Table 1 Baseline characteristics of patients

\begin{tabular}{|c|c|c|c|c|}
\hline Vascular risk factors & Men $(n=296)$ & Women $(n=48)$ & Total $(n=344)$ & $p$ \\
\hline Hypertension & $69,6 \%$ & $70,8 \%$ & $69,8 \%$ & $0,862^{\times 2}$ \\
\hline PAD & $27,7 \%$ & $16,7 \%$ & $26,2 \%$ & $0,107^{\times 2}$ \\
\hline Previous TIA & $7,1 \%$ & $4,2 \%$ & $6,7 \%$ & $0,754^{F}$ \\
\hline Previous Stroke & $10,1 \%$ & $8,3 \%$ & $9,9 \%$ & $>0,999^{F}$ \\
\hline Dyslipidemia & $59,1 \%$ & $64,6 \%$ & $59,9 \%$ & $0,474^{\times 2}$ \\
\hline Smoking & $41,6 \%$ & $10,4 \%$ & $37,2 \%$ & $<0,001 \times 2$ \\
\hline Alcohol & $3,4 \%$ & $0,0 \%$ & $2,9 \%$ & $0,368^{F}$ \\
\hline DM & $33,8 \%$ & $25,0 \%$ & $32,6 \%$ & $0,228 \times 2$ \\
\hline Obesity & $18,9 \%$ & $29,2 \%$ & $20,3 \%$ & $0,102^{\times 2}$ \\
\hline Arrhythmias & $9,1 \%$ & $18,8 \%$ & $10,5 \%$ & $0,043^{\times 2}$ \\
\hline Ischemic heart disease & $26,0 \%$ & $14,6 \%$ & $24,4 \%$ & $0,087^{\times 2}$ \\
\hline Cervical radiotherapy & $2,4 \%$ & $2,1 \%$ & $2,3 \%$ & $>0,999^{F}$ \\
\hline
\end{tabular}

X2: Chi-squared test; F: Fisher's exact tests

related deaths due to comorbidity. Two patients died from intraparenchymal hemorrhage and two from ischemic stroke, one ipsilateral to the treated carotid artery and the other, contralateral to the treated carotid artery. Among the non-neurological deaths, there were 5 cases of vascular death: 3 cases due to chronic ischemia of the lower extremities, and 2 due to acute myocardial infarction (Fig 1).

During the follow-up period, 8 strokes and 3 TIAs were diagnosed (3.2\%). The majority of the strokes (75\%) were contralateral to the treated carotid artery and most were ischemic. We did not identify any predictive risk factors or any procedural characteristics for ipsilateral neurological complication.

ISR was assessed in $4.4 \%$ of the patients and remained asymptomatic in all but 2 patients $(0.6 \%)$. All patients with restenosis underwent revascularization with balloon angioplasty. No stent fracture was observed. Pre-stent angioplasty was significantly associated with the incidence of ISR (Table 5). Risk factors were neither related to neurological complications nor ISR. Further, there were significant differences between the degree of restenosis and the time of its appearance: the greater the degree of restenosis, the shorter the post-procedure time period $(r=-0.426$; $p=0.038$ ). We found no association between restenosis and recurrent events.

Table 2 Peri-procedural complications

\begin{tabular}{lll}
\hline Complications & $\mathrm{n}$ & $\%$ \\
\hline Majors & 8 & $2,3 \%$ \\
MI & 0 & $0,0 \%$ \\
Stroke & 7 & $2,0 \%$ \\
Fatal Stroke (death) & 1 & $0,3 \%$ \\
\hline
\end{tabular}

\section{Discussion}

Stroke is a major cause of mortality and morbidity in industrialized countries. These data, combined with an ever-increasing life expectancy, necessitates that we conduct more detailed analyses of whether carotid revascularization is a safe and effective treatment with which to prevent stroke.

In our series, the 30-day outcomes after CAS show that carotid stenting is an effective treatment in preventing future vascular events, with a low incidence of periprocedural complications: $2.3 \%$ for disabling stroke, death, or MI. Previous systematic reviews of nonrandomized cases series (Kastrup et al., 2003), as well as several studies (Castriota et al., 2002; Cremonesi et al., 2003; Garg et al., 2009; Giri et al., 2015), have shown that EPD-use appears to reduce the incidence of new ischemic lesions. However, various reports have also criticized the use of EPDs in CAS as these devices must pass through the arterial stenosis, which might itself provoke complications (Reimers et al., 2004; Wu et al., 2011) and a greater incidence of microemboli (El-Koussy et al., 2007). Nevertheless, the results of our series show a decreased rate of major complications when EPDs are used $(p=0.005)$, which therefore classifies these devices as protective against stroke.

To our knowledge, our study comprises the largest patient cohort, with the longest national follow-up to compare stroke prevention in patients treated by the same surgical team. In our series, stenting was performed electively as an alternative to endarterectomy. This is because the committee composed by neurologist, radiologist, and interventional radiologist (vascular surgeons refused to participate) decided, more than 15 years ago to send patients directly to CAS, depending on the poor results of the surgery department. Thus, our indications were not limited to patients at a high surgical 
Table 3 The influence of procedural characteristics on peri-procedural complications

\begin{tabular}{|c|c|c|c|c|c|c|c|c|}
\hline \multirow[t]{2}{*}{ Variable } & \multicolumn{4}{|c|}{ Major complicatons } & \multicolumn{4}{|c|}{ Minor complications } \\
\hline & & $n$ & $\%$ & $\mathrm{p}$ & & $n$ & $\%$ & $p$ \\
\hline \multirow[t]{2}{*}{ Ulcer } & No & 8 & $3,3 \%$ & $0,111^{\mathrm{F}}$ & No & 96 & $39,7 \%$ & $0,109^{\times 2}$ \\
\hline & Yes & 0 & $0,0 \%$ & & Yes & 50 & $49,0 \%$ & \\
\hline \multirow[t]{2}{*}{ Pre-stent angioplasty } & No & 8 & $2,5 \%$ & $>0,999^{\mathrm{F}}$ & No & 131 & $40,4 \%$ & $0,002^{\times 2}$ \\
\hline & Yes & 0 & $0,0 \%$ & & Yes & 15 & $75,0 \%$ & \\
\hline \multirow[t]{2}{*}{ EPD } & No & 7 & $5,1 \%$ & $0,005^{\times 2}$ & No & 46 & $33,6 \%$ & $0,007^{\times 2}$ \\
\hline & Yes & 1 & $0,5 \%$ & & Yes & 100 & $48,3 \%$ & \\
\hline \multirow[t]{2}{*}{ Post-stent angioplasty } & No & 2 & $2,2 \%$ & $>0,999^{F}$ & No & 34 & $37,8 \%$ & $0,297^{\times 2}$ \\
\hline & Yes & 6 & $2,4 \%$ & & Yes & 112 & $44,1 \%$ & \\
\hline
\end{tabular}

X2: Chi-squared test; F: Fisher's exact tests

risk. Nevertheless, the risk of periprocedural complication was low, and similar to data from surgical registries with more stringent inclusion criteria (North American Symptomatic Carotid Endoarterectomy Trial Collaboration, 1991; Executive Committee for the Asymptomatic Carotid Atherosclerosis Study, 1995).

The CREST study showed no significant differences between stent and endarterectomy in terms of the risk of stroke or death over its 10-year follow-up. Indeed, the higher risk of stroke reported for CAS can be attributed to the periprocedural differences between the two groups (Brott et al., 2016; Brott et al., 2010), and the infrequent use of EPDs (El-Koussy et al., 2007). Other randomized trials comparing both techniques have been reported, and showed no significant differences after long-term follow-up (Bonati et al., 2015; Gurm et al., 2008; Mas et al., 2008).

Our data appears to indicate that CAS is preventive against ipsilateral stroke with a low long-term risk of severe stroke The recurrence rate in our series of 3.2\% primarily involved strokes contralateral $(75 \%)$ to the treated carotid artery, and most were ischemic. This finding has also been reported in previous related studies in which no significant difference in cumulative rates of fatal or disabling stroke were found for stenting vs. endarterectomy (Bonati et al., 2015; Mas et al., 2008). It is interesting to note that our observed stroke rate of $3.2 \%$ is (fairly) consistent with, and even lower than the $8.5 \%$ reported in the ECST at 3 years (European Carotid Surgery Trial, 1998), and the 13\% rate of the NASCET (North American Symptomatic Carotid

Table 4 Follow-up period

\begin{tabular}{lllllll}
\hline Follow-up (months) & $\mathrm{n}$ & $\%$ & Average & $\mathrm{SD}$ & Median & $(\mathrm{IQR})$ \\
\hline Keep in follow-up & 238 & $69,19 \%$ & 56,40 & 36,30 & 48,90 & $(59,50)$ \\
Loss to follow-up & 50 & $14,53 \%$ & 34,08 & 29,28 & 30,04 & $(41,50)$ \\
Neurological death & 4 & $1,16 \%$ & 10,36 & 10,69 & 8,14 & $(19,25)$ \\
No neurological death & 52 & $15,12 \%$ & 38,33 & 31,28 & 35,53 & $(44,50)$ \\
\hline
\end{tabular}

Endoarterectomy Trial Collaboration, 1991). However, our patient population was closely monitored in terms of risk factors, which may have lowered our rate of complication. Regarding risk factors, Donato et al. (de Donato et al., 2008) and Brooks et al. (Brooks et al., 2014) found that being symptomatic at the time of enrollment and intervention was a good predictor of early and late neurological complication. We failed to find any risk factor associated with late neurological complications, although this may be related to our low recurrence rate.

Prevention of ipsilateral stroke is the ultimate goal of any treatment for carotid stenosis. However, durability, defined as patency determined by Doppler ultrasound, may also serve as a useful definition of therapeutic utility. Our analysis of long-term outcomes showed that the long-term rate of restenosis after stenting was low (4.4\%), and comparable, or even lower, than those achieved with CEA. However, direct comparisons are complicated by the criteria used to make a diagnosis in Doppler sonography. Of the restenosis cases, only 2 $(0.6 \%)$ were symptomatic. We found no association between restenosis and recurrent events, but pre-stent angioplasty was significantly associated with the incidence of ISR. This is difficult to interpret given the small number of recurrent events, pre-stent angioplasty, and restenoses seen in our study. A certain amount of controversy surrounds the issue of long-term rates of restenosis after stenting vs. endarterectomy. Some trials (Bonati et al., 2015; Brott et al., 2016; Mas et al., 2008) have demonstrated no differences when comparing both techniques. For example, 5-year risks of $10.8 \%$ vs. $8.6 \%, 3$-year risks of $3.3 \%$ vs. $2.8 \%$, and 2 -year risks of $6.0 \%$ vs. $6.3 \%$, for stenting vs. endarterectomy, have been reported, respectively. In contrast, the CAVATAS (Bonati et al., 2009) and SPACE trials (Eckstein et al., 2008) reported higher rates of restenosis 2 years after treatment in the stenting group vs. endarterectomy group ( $10.7 \%$ vs. $4.6 \%)$. Consequently, further studies are needed to compare the rate of 


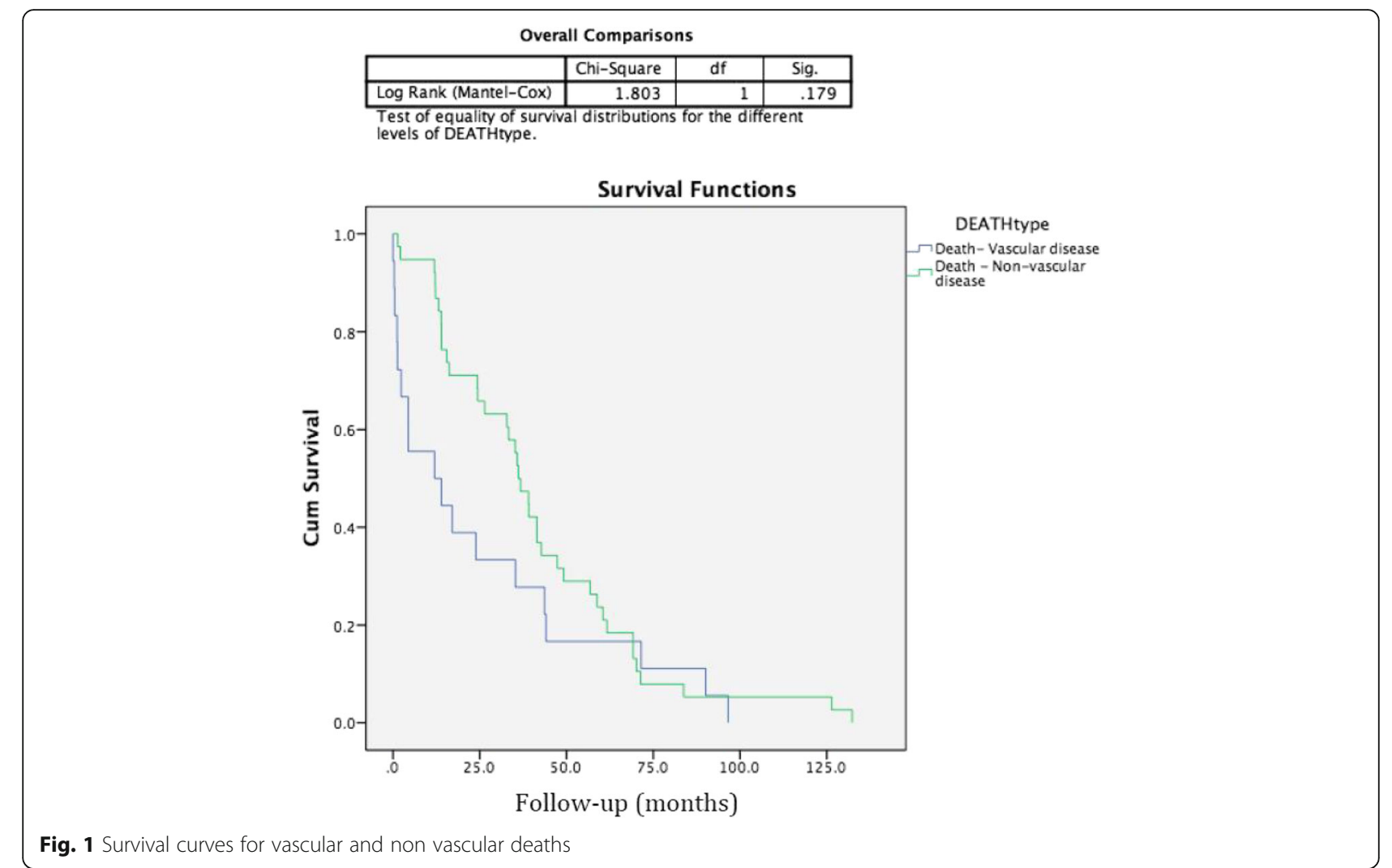

restenosis and to investigate the association between restenosis and recurrent stroke.

The current study has several limitations. The main limitation was its small sample size and retrospective design. Moreover, results obtained in this study were compared with the literature, as it was not possible to undertake a randomized comparison of CAS versus CEA. Further, the efficacy of the EPDs could not be evaluated throughout the entirety of this study as these devices were not available until 2005.

\section{Conclusion}

The long-term follow-up results of our study validate CAS as a safe and durable procedure with which to prevent ipsilateral stroke. Our data also suggest that CAS is

Table 5 The influence of procedural characteristics on restenosis

\begin{tabular}{lllll}
\hline Proceure & Reestenosis & $n$ & $\%$ & $\mathrm{p}$ \\
\hline Peri-procedural complications & No & 142 & $6,8 \%$ & $0,866^{\times 2}$ \\
& Yes & 152 & $7,2 \%$ & \\
Pre-stent angioplasty & No & 322 & $5,6 \%$ & $0,001^{\mathrm{LR}}$ \\
& Yes & 20 & $25,0 \%$ & \\
Post-stent angioplasty & No & 77 & $9,1 \%$ & $0,353^{\mathrm{LR}}$ \\
& Yes & 254 & $6,3 \%$ &
\end{tabular}

X2: Chi-squared test; LR: likelihood ratios effective in terms of long-term functional outcome and risk of fatal or disabling stroke. Post CAS restenosis was infrequent, and, in the majority of cases, asymptomatic.

\section{Abbreviations}

CAS: Carotid artery stent; CCA: Common carotid artery; CEA: Carotid artery endarterectomy; CFA: Common femoral artery; CT: Computerized axial tomography scan; ECA: External carotid artery; EPD: Embolic protection device; IRs: Interventional radiologists; ISR: Intra-stent restenosis; MI: Myocardial infarction; MRI scans: Magnetic resonance imaging; PAD: Peripheral artery disease; PSV: Peak systolic velocity; TIA: Transient ischemic attack

\section{Acknowledgements}

Not applicable.

\section{Ethical approval}

The study has been approved by the Ethics Committee in our Hospital.

\section{Availability of data and materials}

Authors confirm that all relevant data are included in the article and/or its supplementary information files: The authors declare that the data supporting the findings of this study are available within the article [and its supplementary information files].

\section{Authors' contributions}

VMC conceived of the study, and participated in its design and coordination, and draft the manuscript. JAGO participated in the design of the study and helped to performed the statistical analysis. CTJ, MJGP and CPL conceived of the study, and participated in its design and coordination. IDBG performed the statistical analysis and helped to draft the manuscript. MAGA conceived of the study, and participated in its design and coordination and helped to draft the manuscript. All authors read and approved the final manuscript. 


\section{Consent for publication}

All patients agreed to, and provided, written (signed) informed consent which included consent to publish the results as long as it was anonymous.

\section{Competing interests}

The authors declare no financial and non-financial competing interests.

\section{Publisher's Note}

Springer Nature remains neutral with regard to jurisdictional claims in published maps and institutional affiliations.

\section{Author details}

GITMI (Grupo de Investigación en Tecnicas de Minima Invasión) del Gobierno de Aragon, Zaragoza, Spain. ${ }^{2}$ Servicio de Radiología intervencionista, Hospital Clínico Universitario Lozano Blesa, Avenida San Juan Bosco 15, 50009 Zaragoza, Spain. ${ }^{3}$ Servicio de Neurología, Hospital Clínico Universitario Lozano Blesa, Zaragoza, Spain. ${ }^{4}$ Departamento de Patología Animal, Facultad de Veterinaria, Zaragoza, Spain.

\section{Received: 2 January 2018 Accepted: 2 May 2018}

\section{Published online: 17 July 2018}

\section{References}

Bonati LH, Ederle J, McCabe DJ, Dobson J, Featherstone RL, Gaines PA, Beard JD, Venables GS, Markus HS, Clifton A, Sandercock P, Brown MM (2009) CAVATAS investigators: long-term risk of carotid restenosis in patients randomly assigned to endovascular treatment or endarterectomy in the carotid and vertebral artery transluminal angioplasty study (CAVATAS): long-term followup of a randomised trial. Lancet Neurol 8:908-917

Bonati LH, Dobson J, Featherstone RL, Ederle J, der WorpHB v, de Borst GJ, Mali WP, Beard JD, Cleveland T, Engelter ST, Lyrer PA, Ford GA, Dorman PJ, Brown MM (2015) International carotid stenting study investigators: long-term outcomes after stenting versus endarterectomy for treatment of symptomatic carotid stenosis: the international carotid stenting study (ICSS) randomised trial. Lancet 385:529-538

Brooks WH, Jones MR, Gisler P, McClure RR, Coleman TC, Breathitt L, Spear C (2014) Carotid angioplasty with stenting versus endarterectomy: 10-year randomized trial in a community hospital. JACC Cardiovasc Interv 7:163-168

Brott TG, Hobson RW II, Howard G, Roubin GS, Clark WM, Brooks W, Mackey A, Hill MD, Leimgruber PP, Sheffet AJ, Howard VJ, Moore WS, Voeks JH, Hopkins LN, Cutlip DE, Cohen DJ, Popma JJ, Ferguson RD, Cohen SN, Blackshear JL, Silver FL, Mohr JP, Lal BK, Meschia JF (2010) CREST investigators: stenting versus endarterectomy for treatment of carotid-artery stenosis. N Engl J Med 363:11-23

Brott TG, Howard G, Roubin GS, Meschia JF, Mackey A, Brooks W, Moore WS, Hill MD, Mantese VA, Clark WM, Timaran CH, Heck D, Leimgruber PP, Sheffet AJ, Howard VJ, Chaturvedi S, Lal BK, Voeks JH, Hobson RW 2nd (2016) CREST Investigators. Long- term results of stenting versus endarterectomy for carotid-artery stenosis. N Engl J Med 374:1021-1031

Castriota F, Cremonesi A, Manetti R, Liso A, Oshola K, Ricci E, Balestra G (2002) Impact of cerebral protection devices on early outcome of carotid stenting. J Endovasc Ther 9:786-792

Chaturvedi S, Bruno A, Feasby T, Holloway R, Benavente O, Cohen SN, Cote R, Hess D, Saver J, Spence JD, Stern B, Wilterdink J (2005) Carotid endarterectomy-an evidence-based review: report of the therapeutics and technology assessment Subcommittee of the American Academy of neurology. Neurology 65:794-801

Coutts SB, Hill MD, Campos CR, Choi YB, Subramaniam S, Kosior JC, Demchuk AM (2008) VISION study group: recurrent events in transient ischemic attack and minor stroke. What events are happening and to which patients? Stroke 39: 2461-2466

Cremonesi A, Manetti R, Setacci F, Setacci C, Castriota F (2003) Protected carotid stenting: clinical advantages and complications of embolic protection devices in 442 consecutive patients. Stroke 34:1936-1941

de Donato G, Setacci C, Deloose K, Peeters P, Cremonesi A, Bosiers M (2008) Long-term results of carotid artery stenting. J Vasc Surg 48:1431-1440

Dorn F, Liebig T, Muenzel D, Meier R, Poppert H, Rummeny EJ, Huber A (2012) Order of CT stroke protocol (CTA before or after CTP): impact on image quality. Neuroradiology 54:105-112

Eckstein HH, Ringleb P, Allenberg JR, Berger J, Fraedrich G, Hacke W, Hennerici M, Stingele R, Fiehler J, Zeumer H, Jansen O (2008) Results of the stent- protected angioplasty versus carotid endarterectomy (SPACE) study to treat symptomatic stenoses at 2 years: a multinational, prospective, randomised trial. Lancet Neurol 7:893-902

El-Koussy M, Schroth G, Do DD, Gralla J, Nedeltchev K, von Bredow F, Remonda L, Brekenfeld C (2007) Periprocedural embolic events related to carotid artery stenting detected by diffusion-weighted MRl: comparison between proximal and distal embolus protection devices. J Endovasc Ther 14:293-303

European Carotid Surgery Trial (1998) Randomised trial of endarterectomy for recently symptomatic carotid stenosis: final results of the MRC European carotid surgery trial (ECST). Lancet 351:1379-1387

Executive Committee for the Asymptomatic Carotid Atherosclerosis Study (1995) Endarterectomy for asymptomatic carotid artery stenosis. JAMA 273:1421-1428

Furie KL, Kasner SE, Adams RJ, Albers GW, Bush RL, Fagan SC, Halperin JL, Johnston SC, Katzan I, Kernan WN, Mitchell PH, Ovbiagele B, Palesch YY, Sacco RL, Schwamm LH, Wassertheil-Smoller S, Turan TN, Wentworth D (2011) American Heart Association Stroke Council, Council on Cardiovascular Nursing, Council on Clinical Cardiology, and Interdisciplinary Council on Quality of Care and Outcomes Research: Guidelines for the prevention of stroke in patients with stroke or transient ischemic attack: a guideline for healthcare professionals from the american heart association/american stroke association. Stroke 42:227-227

Garg N, Karagiorgos N, Pisimisis GT, Sohal DP, Longo GM, Johanning JM, Lynch TG, Pipinos II (2009) Cerebral protection devices reduce periprocedural strokes during carotid angioplasty and stenting: a systematic review of the current literature. J Endovasc Ther 16:412-427

Giri J, Parikh SA, Kennedy KF, Weinberg I, Donaldson C, Hawkins BM, McCormick DJ, Jackson B, Armstrong EJ, Ramchand P, White CJ, Jaff MR, Rosenfield K, Yeh RW (2015) Proximal versus distal embolic protection for carotid artery stenting: a national cardiovascular data registry analysis. JACC CardiovasC Interv 8:609-615

Gurm HS, Yadav JS, Fayad P, Katzen BT, Mishkel GJ, Bajwa TK, Ansel G, Strickman NE, Wang H, Cohen SA, Massaro JM, Cutlip DE (2008) SAPPHIRE investigators: long-term results of carotid stenting versus endarterectomy in high-risk patients. N Engl J Med 358:1572-1579

Higashida RT, Meyers PM, Phatouros CC, Connors JJ 3rd, Barr JD, Sacks D (2009) Technology assessment committees of the American Society of Interventional and Therapeutic Neuroradiology; Society of Interventional Radiology. Reporting standards for carotid artery angioplasty and stent placement. J Vasc Interv Radiol 20:S349-S373

Kastrup A, Groschel K, Krapf H, Brehm BR, Dichgans J, Schulz JB (2003) Early outcome of carotid angioplasty and stenting with and without cerebral protection devices: a systematic review of the literature. Stroke 34:813-819

Kernan WN, Ovbiagele B, Black HR, Bravata DM, Chimowitz MI, Ezekowitz MD et al (2014) American Heart Association stroke council, council on cardiovascular and stroke nursing, council on clinical cardiology, and council on peripheral vascular disease. Guidelines for the prevention of stroke in patients with stroke and transient ischemic attack: a guideline for healthcare professionals from the American Heart Association/American Stroke Association. Stroke 45:2160-2236

Mas JL, Trinquart L, Leys D, Albucher JF, Rousseau H, Viguier A, Bossavy JP, Denis B, Piquet P, Garnier P, Viader F, Touzé E, Julia P, Giroud M, Krause D, Hosseini $H$, Becquemin JP, Hinzelin G, Houdart E, Hénon H, Neau JP, Bracard S, Onnient Y, Padovani R, Chatellier G (2008) EVA-3S investigators: endarterectomy versus angioplasty in patients with symptomatic severe carotid stenosis (EVA-3S) trial: results up to 4 years from a randomised, multicentre trial. Lancet Neurol 7:885-892

North American Symptomatic Carotid Endoarterectomy Trial Collaboration (1991) Beneficial effect of carotid endarterectomy in symptomatic patients with high grade carotid stenosis. N Engl J Med 325:445-453 NASCET

Reimers B, Schlüter M, Castriota F, Tübler T, Corvaja N, Cernetti C, Manetti R, Picciolo A, Liistro F, Di Mario C, Cremonesi A, Schofer J, Colombo A (2004) Routine use of cerebral protection during carotid artery stenting: results of a multicenter registry of 753 patients. Am J Med 116:217-222

Roger VL, Go AS, Lloyd-Jones DM, Adams RJ, Berry JD, Brown TM, Carnethon MR, Dai S, de Simone G, Ford ES, Fox CS, Fullerton HJ, Gillespie C, Greenlund KJ, Hailpern SM, Heit JA, Ho PM, Howard VJ, Kissela BM, Kittner SJ, Lackland DT, Lichtman JH, Lisabeth LD, Makuc DM, Marcus GM, Marelli A, Matchar DB, MM MD, Meigs JB, Moy CS, Mozaffarian D, Mussolino ME, Nichol G, Paynter NP, Rosamond WD, Sorlie PD, Stafford RS, Turan TN, Turner MB, Wong ND, Wylie-Rosett J, American Heart Association Statistics Committee and Stroke Statistics Subcommittee 
(2011) Heart disease and stroke statistics - 2011 update: a report from the American Heart Association. Circulation 123:e18-e209

Sacco RL, Adams R, Albers G, Alberts MJ, Benavente O, Furie K, Halperin JL, Johnston SC, Katzan I, Kernan WN, Mitchell PH, Ovbiagele B, Palesch YY, Sacco RL, Schwamm LH, Wassertheil-Smoller S, Turan TN, Wentworth D (2006) American Heart Association, American Stroke Association Council on Stroke, Council on Cardiovascular Radiology and Intervention, American Academy of Neurology: Guidelines for prevention of stroke in patients with ischemic stroke or transient ischemic attack: a statement for healthcare professionals from the American Heart Association/American Stroke Association Council on Stroke: co-sponsored by the Council on Cardiovascular Radiology and Intervention: the American Academy of Neurology affirms the value of this guideline. Stroke 37:577-617

Wu YM, Wong HF, Chen YL, Wong MC, Toh CH (2011) Carotid stenting of asymptomatic and symptomatic carotid artery stenoses with and without the use of a distal embolic protection device. Acta Cardiol 66:453-458

\section{Submit your manuscript to a SpringerOpen ${ }^{\circ}$ journal and benefit from:}

- Convenient online submission

- Rigorous peer review

- Open access: articles freely available online

- High visibility within the field

- Retaining the copyright to your article

Submit your next manuscript at $\boldsymbol{s p r i n g e r o p e n . c o m ~}$ 